\title{
La Educación Zapatista como Base de la Autonomía en el Sureste Mexicano
}

\author{
Bruno Baronnet' \\ 'Universidad Veracruzana, Xalapa, Veracruz - México
}

RESUMEN - La Educación Zapatista como Base de la Autonomía en el Sureste Mexicano. Desde la perspectiva de los pueblos mayas zapatistas en Chiapas, la educación tiene como sujetos protagónicos a todos los miembros de la comunidad, quienes a menudo participan directamente mediante un sistema renovado de cargos y asambleas, en la construcción de la escuela, la elección de promotores de educación autónoma y la manutención y formación de los mismos. Con metas emancipadoras basadas en la praxis, los contenidos escolares son propuestos y discutidos por integrantes de las familias, autoridades comunitarias y educadores. A pesar de dificultades en la cotidianidad, la autonomía política educativa garantizaría las especificidades identitarias y organizativas propias de las comunidades indígenas al definir el quehacer educativo.

Palabras-clave: Movimiento Indígena. Política Educativa. Escuela. Identidad. Chiapas.

\begin{abstract}
Zapatista Education as a Basis for Autonomy in South-Eastern Mexico. From the perspective of the Mayan Zapatistas in Chiapas, the subjects promoting education are all the members of the community, who often participate directly through a renewed system of community labours and assemblies, in building schools, choosing autonomous education promoters and in maintaining and training them. With emancipatory goals based on praxis, classroom content is proposed and discussed by members of families, educators and community authorities. Despite difficulties in everyday life, the political autonomy in education guarantees the specific organizational identity of indigenous communities in defining their educational activities. Keywords: Indigenous Movement. Educational Policy. School. Identity. Chiapas.
\end{abstract}

Educação \& Realidade, Porto Alegre, v. 40, n. 3, p. 705-723, jul./sept. 2015. 705 http://dx.doi.org/10.1590/2175-623645794 
La Educación Zapatista como Base de la Autonomía en el Sureste Mexicano

\section{Introducción}

A dos décadas del conocimiento público del ¡Ya Basta! expresado en la Primera Declaración de la Selva Lacandona en 1994 con la que se dio a conocer el grupo armado mexicano conocido como Ejército Zapatista de Liberación Nacional (EZLN), la construcción del proyecto autonómico por derecho propio se mantiene en las entidades territoriales denominadas Municipios Autónomos Rebeldes Zapatistas. Contra viento y marea, los Municipios autónomos mantienen el rumbo del proyecto de construcción de autonomías en sus pueblos mediante una lucha de resistencia a la que no le han faltado iniciativas y propuestas de organización que han trascendido el ámbito local y regional. Iniciativas que se han traducido en la puesta en práctica de sus propios sistemas educativos, de salud, de justicia, de producción y de comercio. Después de casi cuatro lustros, éstas enfrentan la instrumentación estratégica de una guerra de baja intensidad (ocupación de los territorios y apuesta al desgaste de las bases sociales) aplicada por los gobiernos que se han alternado en el poder mediante juegos electorales que no ocultan las lagunas democráticas en el contexto de la globalización de la economía neoliberal y el reconocimiento tímido de la realidad multicultural de México. A las prácticas autoritarias de imposición y represión, los zapatistas se oponen y resisten con dignidad y creatividad al mostrar un alto compromiso con los proyectos de autodesarrollo sustentable, no tanto como vanguardia de los movimientos antisistémicos, sino como un ejemplo entre muchos de la posibilidad de crear "otro mundo donde quepan todos los mundos" según la fórmula expresada por su principal vocero el Subcomandante Insurgente "Marcos", ahora autodenominado "Galeano".

Basado en trabajos etnográficos y análisis de declaraciones recientes $^{1}$, se busca aquí mostrar qué sentido cobra la legitimidad de una alternativa educativa en el marco de la construcción de regiones autónomas dotadas de instituciones y políticas propias de desarrollo autosustentable. A partir del análisis de las prácticas educativas de los pueblos implicados, ¿̇en qué medida la lucha zapatista significa la aparición de formas propias de ejercer los derechos educativos? ¿De qué modo los cambios en la organización comunitaria en torno a la educación básica tienen como consecuencia prácticas pedagógicas que tienden a descolonizar los contenidos curriculares? Si bien las demandas zapatistas se orientan a resignificar y apropiarse la escuela como espacio de afianzamiento de las identidades políticas y socioculturales, al mismo tiempo se trata en cierta forma de analizar un proceso paulatino de construcción educativa que se sostiene y se alimenta de los rasgos y atributos identitarios que dan sentido al pensamiento y a las acciones de los rebeldes. En otras palabras, el presente artículo escudriña las características del impacto de luchas educativas circunscritas a una vasta región sacudida por un movimiento social como el zapatismo, en la medida 
en que se ponen en juego las subjetividades de quienes protagonizan estos cambios a raíz de proyectos regionales participativos que se erigen de cara a las políticas neoindigenistas que buscan controlar social y políticamente a las comunidades originarias, en una zona de la Diócesis de San Cristóbal de Las Casas donde los efectos de la teología de la liberación india parecen haber preparado el terreno para una amplia propuesta de pedagogía de la emancipación en los pueblos mayas de Chiapas.

En un primer momento, este artículo aborda la construcción de políticas comunales de educación indígena y campesina orientadas al ejercicio directo de los derechos a la autonomía, partiendo de elementos históricos que siguen marcando la vida cotidiana de los pueblos en lucha. En un segundo apartado, se muestra cómo las alternativas zapatistas se configuran a nivel pedagógico gracias al aprovechamiento de las condiciones concretas para un aprendizaje situado, de acuerdo a las identidades de varias decenas de miles de niños que han nacido y crecido en medio de las movilizaciones políticas que dan sentido al zapatismo. En un tercer momento, se analizan más en profundidad los retos y las dificultades que enfrentan las familias zapatistas para movilizar recursos propios en el marco de la participación y la incidencia de los sujetos comunitarios en la orientación de los procesos político-pedagógicos ligados al proyecto de Educación Verdadera. Asimismo se investiga en qué sentido las alternativas educativas autonómicas representan una manera de reflejar las identidades indígenas, campesinas y zapatistas en los contenidos escolares, sin dejar de considerar que el ejercicio de estos derechos colectivos contribuye a fortalecer el orgullo y la dignidad de pertenecer a pueblos oprimidos en búsqueda de la emancipación del yugo neocolonial que recobra hoy la forma del sistema capitalista al cual se oponen firmemente. El actuar de organizaciones contestatarias en México que se articulan desde el zapatismo en el Congreso Nacional Indígena participa en la rebelión india a la cual se refiere Margarita Nolasco (2009, p. 24) cuando la caracteriza como "diversa y, sobre todo y hasta ahora, dispersa, de indígenas comprometidos con su realidad”, partiendo del hecho que esta rebelión “[...] busca el cómo seguir siendo indígenas y mexicanos pero ahora iguales, con las mismas oportunidades y con derechos que vayan más allá de lo escrito y se manifiestan en la realidad, esto es, con su lengua y su cultura, orgullosamente adelante".

\section{Políticas Comunales de Educación Indígena y Campesina}

Los pueblos zapatistas tzeltales, tzotziles, choles y tojolabales no han estado esperando medidas de justicia social y cognitiva por parte del Estado para emprender políticas de autogobierno, con considerables esfuerzos a nivel educativo. A principios de 1996 se firmaron los Acuerdos de San Andrés como parte de la primera mesa de negociacio- 
La Educación Zapatista como Base de la Autonomía en el Sureste Mexicano

nes sobre derechos y cultura indígena. Estos acuerdos fueron negociados entre la Comandancia General del EZLN, sus asesores indígenas e intelectuales, y la parte gubernamental (federal y estatal) además de la Comisión de Concordia y Pacificación (COCOPA), conformada por diputados de los distintos partidos políticos con representación en el Congreso de la Unión. Dichos acuerdos, reformulados como Ley COCOPA, fueron reformulados por el gobierno de Ernesto Zedillo, el cual decidió no proceder con su legislación. Esta acción fue interpretada por la comandancia zapatista y por el resto de las organizaciones indígenas, pendientes de las negociaciones y acuerdos de paz, como una traición a sus aspiraciones ${ }^{2}$. A nivel educativo, las autoridades gubernamentales se comprometieron en los Acuerdos de San Andrés, pero sin seguimiento ni cumplimiento posterior, a asegurar a los indígenas una educación que respete y aproveche sus saberes, tradiciones y formas de organización.

Como parte de una estrategia para burlar el cerco militar que pretendía mantener a raya a la insurgencia zapatista, el EZLN empezó a impulsar desde finales de 1994 la municipalización de los territorios bajo su influencia y anunció en 2003 la creación de Juntas de Buen Gobierno en cinco regiones denominadas 'Caracoles' que federan a los nuevos municipios. En espacios regionales, las bases de apoyo y sus simpatizantes se dan a la tarea de poner en práctica los derechos reconocidos en el artículo $2^{\text {do }}$ constitucional que "reconoce y garantiza el derecho de los pueblos y las comunidades indígenas a la libre determinación” (Stavenhagen, 2013). La construcción de facto de autonomías políticas aparece entonces como una respuesta popular a la negación del gobierno y la clase política de cumplir con lo que se había acordado en las mesas de negociación, proceso hasta hoy suspendido.

Así, a lo largo del camino de lucha y resistencia, las bases zapatistas ponen en práctica y valorizan conocimientos y saberes que ayuden a fortalecer su identidad como militantes de una organización político-armada; esto es como autónomos, como indígenas campesinos y mexicanos, identidad que puede apreciarse en los símbolos con los que se manifiestan, en el himno y corridos neozapatistas, las banderas mexicana y rojinegra que enarbolan. El significado que cobra la autonomía, se da con base en el control del territorio y no en una mera declaración propagandística con fines de reafirmar una identidad ideológica. La autonomía por lo tanto se define como un proceso de construcción en tiempo y espacio no concedido por el Estado sino asumido como una conquista puesta en práctica (Zibechi, 2008). En este sentido, más adelante se abordan los aportes zapatistas a la construcción de la autonomía educativa que se basan en principios democráticos y éticos ligados a la cultura campesina e indígena y al derecho consuetudinario, cuya normatividad se opone a la del Estado, que considera a los sistemas educativos alternativos como ilegales. Sin embargo, son legítimos desde el punto de vista de los protagonistas que lo constituyen, consolidan y

708 Educação \& Realidade, Porto Alegre, v. 40, n. 3, p. 705-723, jul./sept. 2015. 
evalúan (Baronnet, 2012). Esta legitimidad desde la perspectiva de las bases zapatistas se inscribe en el marco de la conflictividad que las opone a diversos actores cercanos a los partidos políticos en el poder, suscitando así que las escuelas se vuelvan espacios no sólo de disputa entre hermanos indígenas sino de lucha prefigurativa por la implementación de los derechos autonómicos ante el 'delito' de ejercerlos. De acuerdo con una denuncia emitida por la Junta de Buen Gobierno de Oventik, el contexto general de la construcción de la red intermunicipal de más de 500 escuelas 'autónomas' se caracteriza por la guerra contrainsurgente que busca restar legitimidad a las alternativas zapatistas, como en el caso de la comunidad tzeltal de San Marcos Avilés (Chilón) donde la creación de la escuela zapatista en 2010 ha suscitado hostigamientos y desplazamientos forzados.

\begin{abstract}
Ya no vamos seguir permitiendo más agresiones y desalojos de nuestros compañeros bases de apoyo; porque nuestros compañeros y compañeras no tienen ninguna culpa, solo porque quieren ejercer sus derechos a la educación, a la salud y a su autonomía. Pero que sepa todo el pueblo de México, que sepa el mundo entero que en Chiapas y en México es delito ejercer los derechos a la educación, a la salud y a la autonomía como pueblos. Porque los únicos delitos que tienen nuestros compañeros por lo que son amenazados, atacados y perseguidos es porque quieren tener su propia educación autónoma para sus hijos, quieren vivir con derechos y con justicia, quieren ser respetados como seres humanos [...]. La Autonomía de los pueblos, es lo que no quieren los malos gobiernos porque quieren seguir teniendo bajo su dominio a los pueblos originarios y les da mucho odio cuando los pueblos indígenas aprendemos a organizamos y a gobernarnos solos, pero como quiera, esta lucha que llevamos ya nadie podrá detenerlo (Junta de Buen Gobierno de Oventik, 2010).
\end{abstract}

Después de haber recuperado miles de hectáreas de tierras cultivables que estaban en manos de familias latifundistas hasta la segunda mitad de la década de los años 90, la ocupación territorial como base de la autonomía en las Cañadas de la Selva Lacandona ha obligado a los nuevos concejeros municipales a asumir el control de la construcción de los sistemas educativos, de salud, de producción y de mercado. Para cubrir las necesidades básicas de sus poblados, los campesinos mayas diseñaron propuestas educativas endógenas que parten del principio del "aprender caminando" para construir una "educación que enseña la verdad", de acuerdo a la perspectiva de los pueblos por "despertar la consciencia". Partiendo de la voz de uno de sus integrantes, los recién publicados Cuadernos de texto de primer grado del curso de "La libertad según los zapatistas" hacen eco de la historia del repudio indígena a las "escuelas oficiales" y de la construcción de la Otra Educación. Por ejemplo, Doroteo que ha sido integrante de la Junta de Buen Gobierno del Municipio Libertad de los Pueblos Mayas, narra lo siguiente: 
La Educación Zapatista como Base de la Autonomía en el Sureste Mexicano

La educación autónoma en nuestra zona empezó desde 1997 [...]. En aquel entonces se empezó a pensar cómo hacer nuestra educación porque allá en nuestra zona hubo un problema con los maestros del sistema de la SEP (Secretaría de Educación Pública), después de 1994 empezaron a tener muchos problemas con los pueblos [...]. Nos vimos obligados a empezar nuestra propia educación aunque en algunos pueblos ya de por sí lo estaban haciendo [...]. Se empieza a pensar qué tienen que aprender nuestros hijos, qué tienen que cambiar del sistema educativo del gobierno (Escuelita Zapatista, 2013, p. 4).

Esta reflexión nace como respuesta de rechazo al diseño centralista de políticas públicas enfocadas a una educación rural que no está encabezada ni aceptada por los sujetos colectivos, es decir, los pueblos y las comunidades organizadas con facultades y con disposiciones favorables para participar activamente en la toma de decisiones y en la evaluación de política social. La apropiación en el imaginario colectivo de instrumentar alternativas a la educación del "mal gobierno" data de antes del levantamiento armado, como relata Abraham, integrante de la Junta de Buen Gobierno del MAREZ San Juan de la Libertad:

En aquel tiempo, antes del 94, de por sí se había tenido la idea de llevar una educación del pueblo, para el pueblo y por el pueblo. Son ideas que vienen surgiendo desde antes pero no se podían concretizar en ninguna forma porque ahí estaban las escuelas oficiales del 'mal gobierno', esa idea se vino alimentando poco a poco y durante varios años la teníamos guardada. Ya en el 1994 salen nuestras demandas públicamente, una es la educación, pero solamente en palabras, solamente está nuestra demanda como educación pero no había ninguna receta para saber cómo empezar, cómo lo vamos a construir esa educación del pueblo (Escuelita Zapatista, 2013, p. 16).

Así, la autonomía educativa surge como una de las demandas centrales del movimiento indígena, no solo del zapatista sino a nivel nacional en su búsqueda por emanciparse de la política educativa impuesta por actores ajenos a la realidad comunitaria en el escenario escolar local. El proyecto autonómico de educación comunal funciona en realidad como una escuela de formación de cuadros comprometidos con el movimiento indígena en el cual interactúan en la cultura política local, puesto que se aboca a la enseñanza plurilingüe de la lectoescritura y aritmética básica, en articulación con contenidos de aprendizaje anclados en las demandas de su plataforma de lucha (tierra, techo, trabajo, salud, educación, alimentación, entre otras).

En agosto del año 2001, después de meses de consulta con sus bases y autoridades, los responsables del Municipio autónomo que lleva el nombre del revolucionario anarquista Ricardo Flores Magón elaboran un documento - originalmente escrito en lengua tzeltal - considerado

710 Educação \& Realidade, Porto Alegre, v. 40, n. 3, p. 705-723, jul./sept. 2015. 
directriz de lo que a su manera plantean como 'Educación Verdadera'. Sus objetivos y contenidos se originan en la experiencia histórica en su relación con el sistema educativo nacional, el cual es cuestionado y rechazado por considerar que no toma en cuenta los valores, culturas, lenguas e historias de los pueblos originarios de México y América. Como práctica democrática del mandar obedeciendo, las propuestas educativas en sus contenidos y maneras de hacer surgen del consenso, la reflexión y la experiencia. Se llega así a la conclusión de que una Educación Verdadera emerge de las palabras y conocimientos en el que todos los sujetos, en colectivo, deben de “[...] comenzar a aprender con los niños, mujeres, hombres y ancianos para que así vamos a lograr nuestra lucha” (Municipio Autónomo en Rebeldía Ricardo Flores Magón, 2001). En este sentido, la enseñanza impartida por los y las docentes comunitarios denominados "promotores y promotoras de educación autónoma” (nopteswanej o promotoretik en lengua tzeltal) está orientada hacia fines prácticos bien marcados, es decir:

\begin{abstract}
Enseñarnos a resolver el problema del pueblo, vamos a saber siempre para qué sirven las cosas que vemos y así vamos a hacer nuestro propio camino para resolver nuestras demandas y nuestros promotores poco a poco apoyan a su comunidad y la comunidad apoya a sus promotores y así va a respetar y valorar la educación autónoma y así nos hacemos ejemplo para otras organizaciones (Municipio Autónomo en Rebeldía Ricardo Flores Magón, 2001).
\end{abstract}

Representando fuentes éticas de inspiración por su ejemplaridad percibida más allá de Chiapas ${ }^{3}$, los Concejos Autónomos rebeldes que componen a cada uno de los cinco Caracoles se encuentran actuando como los representantes quienes impulsan y coordinan los esfuerzos militantes en torno a la formación de una política comunal de educación, en la cual los campesinos mayas participan colectivamente de manera a incidir en los procesos de decisión y de gestión de los asuntos escolares. Los miembros en turno de los Concejos monitorean las obras y los proyectos comunitarios en una microrregión. En vez de recibir salarios, tanto las autoridades autónomas como los promotores de educación reciben el apoyo de los hombres de la comunidad para colaborar con la alimentación de su familia y para mantener su parcela de cultivos de frijol y de maíz.

En Chiapas, las comunidades que sostienen al movimiento se auto-reconocen e identifican como comunidades autónomas quienes se encargan de conducir proyectos municipales de Educación Verdadera que contribuyen a enorgullecer a los propios portadores de las identidades zapatistas, mayas y campesinas que se ven reflejadas en las pedagogías puestas en práctica. El presente artículo concuerda con el análisis de Horacio Gómez Lara (2011), quien fuese antropólogo de origen tzotzil, cuando menciona que más allá de las escuelas zapatistas que tienen objetivos específicos como 'la reproducción del movimiento', los 
La Educación Zapatista como Base de la Autonomía en el Sureste Mexicano

niños también “[...] están aprendiendo en los espacios de trabajo según su género: la milpa, los montes, la comunidad, la casa, la cocina, respectivamente; con lo que la reproducción de los esquemas mentales de la identidad indígena y campesina queda garantizada" (Gómez Lara, 2011, p. 320). Así, la educación no formal en el seno familiar se articula con los procesos de enseñanza-aprendizaje en el aula, haciendo de la escuela un espacio comunitario estrechamente enlazado con el territorio y los sujetos que lo habitan.

\section{Aprendizaje Situado e Identidades Campesinas y Políticas}

Al considerarse 'compañeras' y 'compañeros', la relación de cercanía entre los promotores de educación y los educandos corresponde a una relación pedagógica simbólicamente menos violenta para los niños en comparación con las escuelas públicas como se muestra en un trabajo etnográfico en un salón de clase zapatista en el pueblo chol de San Miguel (Núñez, 2011, p. 291-292), donde las prácticas educativas revelan conexiones múltiples con la vida cotidiana en el hogar familiar, en la comunidad rural y en la región bajo influencia de los rebeldes. Estas prácticas docentes engendran la incorporación en el aula de diferentes elementos culturales de la socialización de los niños en el hogar, como la valorización de la palabra y los conocimientos de los ancianos, el respeto de la libertad de los más jóvenes para unirse al grupo de los hermanos mayores y la inclinación de aquellos para apoyarlos. En los procesos de aprendizaje situado, es decir contextualizado y contextualizante, la indagación comunitaria, los talleres colaborativos y la cooperación entre los educandos se erigen como herramientas de una educación problematizadora tendiente a politizar las identidades campesinas y políticas de acuerdo a la necesidad de fortalecer y renovar un movimiento social capaz de forjar subjetividades críticas de la realidad y de su propia congruencia.

En cierta medida, la pedagogía dignificante propuesta por Paulo Freire sería más actual que nunca en las regiones zapatistas, demostrando que la educación no cambia al mundo sino empodera a las personas que lo harán. Desde esta óptica, “[...] no hay práctica pedagógica que no parta de lo concreto cultural e histórico del grupo con quien se trabajó" (Freire, 1986, p. 143). La educación autónoma se inscribe así en las tradiciones de la pedagogía crítica socialista y antirracista que apunta a fortalecer las capacidades de reflexión y acción cultural y política de determinados grupos discriminados, al buscar además soluciones pragmáticas para tomar el control popular de las escuelas en sus territorios y tratar de disputar al Estado su hegemonía en la elaboración de planes curriculares. Si bien la educación liberadora de inspiración freiriana busca generar cierta transformación de las estructuras de dominación, parece difícil que desde un sistema escolar renovado pueda surgir una revolución cultural entendida como esfuerzo máximo de concientización ${ }^{4}$.

712 Educação \& Realidade, Porto Alegre, v. 40, n. 3, p. 705-723, jul./sept. 2015. 
En efecto, las comunidades zapatistas - incluyendo por cierto a la niñez - son grupos sociocultural y políticamente insertos en una dinámica de organización regional; tienen un alto grado de conciencia crítica. Sus propios integrantes y simpatizantes además no callan algunas discrepancias con las autoridades autónomas y a veces con el mismo EZLN. La toma de conciencia colectiva de su explotación y discriminación no es reciente ya que proviene de la trayectoria militante de las familias mayas en las filas de organizaciones campesinas locales y después en el zapatismo armado y civil (Baronnet, 2011, p. 138-139). Es preciso relativizar la realidad de la concientización de la niñez zapatista por medio de la escuela, ya que los procesos de socialización política ocurren de antemano en los diversos ámbitos familiares, religiosos, asamblearios y festivos propios de la comunidad y de su red organizativa regional. En este sentido, considerar a la escuela zapatista como la instancia principal de socialización política en los territorios controlados por las bases de apoyo del EZLN sería negar el papel formador de las familias desde la infancia y de la participación en actos públicos como las asambleas, las misas y demás actividades de movilización local.

En las pequeñas comunidades rurales que pertenecen a los $\mathrm{Mu}-$ nicipios autónomos, las implicaciones de la lucha zapatista en la educación transforman la utilización de los tiempos y los espacios dedicados al estudio y el aprendizaje en la escuela. Un aspecto clave de la autonomía educativa es la flexibilidad en el uso del tiempo que permite la gestión participativa, implicando que los horarios y calendarios escolares se adapten a las actividades agrícolas, cívicas y religiosas, a las condiciones de guerra de desgaste y de movilización política, así como a las necesidades de formación del docente fuera de la aldea. Otros cambios considerables corresponden a la apropiación del espacio escolar como un espacio construido y organizado de una manera bastante cercana a las formas de edificar y de mantener los domicilios de las familias implicadas en los proyectos autonómicos.

Las iniciativas comunales de reinvención de la escuela en Chiapas se desarrollan a partir de las condiciones y las necesidades establecidas, lejos de las instituciones burocráticas de intermediación, de supervisión administrativa y de control político y sindical. Descansan en principios de pedagogía comunitaria crítica que contribuyen a fomentar un aprendizaje situado y transversal. En términos generales, a pesar de ser casi reducido a la educación de base, el currículo comunal que está inventado, estructurado y transformado en permanencia en las escuelas (Dietz; Mateos, 2011, p. 132), enfocándose en las condiciones locales que son el punto de partida del aprendizaje significativo e inductivo, consciente de las asimetrías de la sociedad contemporánea, refutando una estandarización y una homogenización de los procedimientos de alfabetización, de organización y de evaluación. En el contexto del movimiento indígena, los procesos de alfabetización no corresponden realmente a un repliegue identitario, incluso una voluntad separatista, 
La Educación Zapatista como Base de la Autonomía en el Sureste Mexicano

sino a la afirmación de una diferencia lingüística, cultural y sociopolítico que potencializa el ejercicio de los derechos a la autodeterminación en la educación.

Representando cierto aprovechamiento de las identidades político-culturales en la arena educativa, la asamblea comunal y las instancias internas de deliberación en las comunidades autónomas de Chiapas delegan y controlan los poderes asumidos por el educador a partir de un cargo resignificado y adquirido con base en el reconocimiento consensuado de su capacidad, prestigio y trayectoria personal en la vida política cotidiana local. El trabajo docente no sólo se legitima por pura disponibilidad y entrega como militante a favor del proyecto político comunal, sino que también recibe el reconocimiento de las autoridades municipales y regionales, así como de las redes de solidaridad nacional e internacional. El cargo de promotor zapatista de educación se ubica también en un marco democrático flexible que posibilita la rotación, la remoción y la rendición de cuentas por su desempeño. En lugar de percibir un sueldo, el prestigio o la autoridad moral adquirido a lo largo de la práctica del cargo posiciona al (ex) promotor de educación autónoma como un agente comunitario clave en la realidad social y en el imaginario político regional, ya que se reconoce su acción desinteresada materialmente que está contribuyendo a legitimar en las nuevas generaciones la valoración de la diferencia social, cultural y política de los compañeros autónomos.

De alguna manera, un elemento fundamental que está en juego en la escuela zapatista se refiere a la toma de conciencia de las especificidades identitarias situadas en el imaginario regional en relación a la cultura nacional occidentalizada. De manera general, la escuela no solo ha tenido como función consagrar la 'distinción' de las clases cultivadas, porque opone una 'cultura sabia' vehiculada por la escuela a una 'cultura popular' de los que son excluidos de ella, considerando según Bourdieu (1967) que estos dos esquemas de percepción, de lenguaje, de pensamiento y de aprendizaje separan los que los reciben del resto de la sociedad. Los modos endógenos de legitimación de la cultura popular por medio de la escuela corresponden precisamente a uno de los principales desafíos para los proyectos de educación de niños y de adultos que participan en los movimientos sociales de los pueblos originarios. Detrás de las funciones de alfabetización, la experiencia social en el campo educativo es el objeto de ilusiones (y desilusiones), de simulaciones (y disimulaciones) y de relaciones de dominación y resistencia social, en torno a su eficacia o su capacidad para revitalizar las lenguas y dignificar las identidades, así como para potenciar la formación de cuadros políticos y activistas culturales desde el 'habitus rebelde' (Gómez Lara, 2011) y comprometidos con la lucha por mejores condiciones colectivas de existencia.

En el campo social de la educación, diferentes formas de discriminaciones institucionales se pueden analizar a través del estudio de 
los problemas de acceso y niveles de calidad y pertinencia de la educación destinada a los niños en los pueblos originarios, afrodescendientes y a los hijos de trabajadores migrantes. Como forma más implícita de discriminación, debemos tomar en cuenta las consecuencias de las violencias simbólicas que Pierre Bourdieu (1990) definió como el "racismo de la inteligencia", mediante el cual se descalifica a las personas y los grupos que tienen formas no escolares de producir y reproducir conocimientos y saberes que les son propios, pero que son despreciados, manipulados y reprimidos por las principales instituciones educativas. Por ejemplo, se trata de conocimientos que tienen que ver con el medioambiente, la artesanía o la medicina tradicional. Algunos grupos sociales han incorporado y aceptado la descalificación de sus saberes tradicionales, es decir la colonización interna, y se resignan ante el desconocimiento y la valoración negativa de conocimientos diferenciados por medio de su enseñanza y aprendizaje en la escuela. Se llega así a percibir que los únicos conocimientos y saberes válidos son los que se construyen y se difunden en la escuela.

En distintas regiones rurales y multiétnicas de América Latina, la escuela 'monocultural' se impone ahora como el modelo educativo dominante de herencia colonial, ajena y enajenante. En los países del Sur donde los pueblos se enfrentan hoy a procesos de neocolonialismo, la adquisición y el manejo de los saberes son la clave de la participación en la vida económica, social y política, en contextos en los cuales la escolarización se extiende y las desigualdades crecen, mientras que las prácticas tienden a alinearse en distintos grados en las normas escolares internacionales (Henaff; Lange, 2011). A diferencia de zonas de África donde los Estados habían abierto pocas escuelas y donde el descompromiso público ha provocado una explosión de iniciativas privadas y comunitarias, las cuales están a menudo a cargo de las poblaciones (Henaff; Lange, 2011, p. 13), en las zonas de influencia zapatista la ausencia relativa del Estado en materia educativa no ha sido suplantada por asociaciones civiles y religiosas, pero sí por la coordinación y la articulación de nuevas autoridades públicas en los niveles comunales e intercomunales. Con la ayuda de simpatizantes del movimiento, ellas han impulsado la creación, la aceptación y el reconocimiento de redes de escuelas que mezclan e imaginan pedagogías que se encuentran encaminadas a formas escolares de educación popular, incorporando los conocimientos indagados en las culturas locales, las memorias de la lucha cotidiana para la supervivencia y la resistencia político-cultural.

La acción autónoma de los sujetos educativos y la toma directa de decisiones en materia de contenidos y métodos, planeación curricular y evaluación permiten así aprovechar la vitalidad de las instituciones comunitarias y los lazos de solidaridad existentes, como elementos para generar y potenciar formas de trabajo escolar y pedagógico. Podemos entonces considerar las demandas de descolonizar la producción y circulación de conocimientos diferenciados, destacando los diálogos de 
La Educación Zapatista como Base de la Autonomía en el Sureste Mexicano

saberes y los efectos del multiculturalismo neoliberal en relación a las identidades culturales y las prácticas de enseñanza. La refundación del Estado requiere una educación para la democracia intercultural (Santos, 2010), es decir una educación para la autonomía, para aprender a construir autonomías a nivel colectivo desde las subjetividades y las memorias históricas. Como estrategias de autonomía, se replantea hacer de cada individuo un ser crítico y decolonial capaz de gobernar y ser gobernado de acuerdo a un proyecto autogenerado y sustentable. Frente a la desvalorización de los conocimientos propios, una tarea estratégica de los proyectos educativos alternativos tendería a contrarrestar mejor los efectos de la colonización del imaginario y la interiorización de la dominación simbólica. Esta transformación profunda limitaría los racismos y la incorporación de la creencia en una supuesta incapacidad de los pueblos y sus representantes para cumplir con las tareas de docencia y de gestión regular de las escuelas.

\section{Retos de la Participación y Reafirmación Identitaria}

En cierta medida, las prácticas autonómicas son el resultado de lógicas de politización de las identidades que contribuyen a la legitimación de prácticas creativas de alfabetización ubicadas en la imaginación, las subjetividades y los atributos identitarios de los campesinos mayas en lucha. La lucha política por implementar un modelo endógeno de alfabetización y formación humana y ética corresponde a las estrategias del ejercicio de ciudadanos y activistas indígenas en la construcción de Otra Educación, multilingüe e intercultural, crítica y emancipadora, popular y científica, que se articula con las demandas zapatistas y las aspiraciones de 'justicia, democracia y libertad'. De acuerdo a declaraciones públicas de la Comandanta Insurgente Rosalinda, los zapatistas luchan por una educación “[...] concientizada, conciliadora y liberadora, es decir, una educación de acuerdo con nuestra vida, con

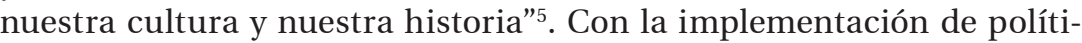
cas municipales de educación intercultural crítica, la lucha zapatista contra el analfabetismo se inscribe en los procesos de afirmación de los derechos colectivos, de los valores y los saberes tradicionales, a pesar de las condiciones de guerra, de recursos materiales y de capacidades pedagógico-didácticas a veces limitadas.

Entre los factores que bloquean o son disfuncionales en los proyectos municipales de educación autónoma, se encuentran las disparidades en la participación activa y directa del conjunto de la población de las aldeas de los Municipios zapatistas, lo que contribuye a veces a un cierto déficit de legitimidad y de control local sobre los procesos alternativos de alfabetización maya (Baronnet, 2013, p. 150). En efecto las mujeres y las personas de edad avanzada no siempre asisten sistemáticamente a las reuniones dedicadas a los asuntos educativos, mientras los jóvenes se muestran a veces reticentes para asumir las tareas docen-

716 Educação \& Realidade, Porto Alegre, v. 40, n. 3, p. 705-723, jul./sept. 2015. 
tes, siendo también abiertamente críticos hacia la actuación de los dirigentes político-militares y los límites de los proyectos autonómicos en distintos niveles. Si el trabajo del educador involucrado en el zapatismo se considera como una herramienta ideológica que refuerza la adhesión colectiva al movimiento zapatista, también permite la penetración de los imaginarios y las lenguas indígenas en la escuela así como la modificación de las prácticas de formación y de acción política de las nuevas generaciones. Esto se expresa por ejemplo en la producción de textos comprometidos con los principios del movimiento (poemas, cantos, relatos, teatro, declaraciones públicas) que ensalzan las virtudes de la 'resistencia' ilustrando el hecho que los procesos educativos se fundamentan en lógicas de penetración y de apropiación de la escritura en diferentes aspectos de la vida cotidiana.

No obstante las intenciones de revitalización lingüística, los cambios socioculturales en las prácticas comunes se acompañan también de cierta substitución de las lenguas mayas por el castellano. A pesar de los esfuerzos destinados a promover la presencia efectiva del niño en la escuela y la participación directa de las familias en la gestión escolar y las orientaciones pedagógicas, la alfabetización multilingüe se realiza a menudo en español cuando la lengua maya está presente como lengua de comunicación principal en el aula, lo que contribuye a modificar lentamente las relaciones de dominación cultural y lingüística (Baronnet, 2013, p. 150). Asimismo otra dificultad se refiere a las desigualdades en los ámbitos de la formación docente y de la coordinación y los intercambios en las prácticas pedagógicas de una comunidad autónoma a otra, de una región autónoma a otra. Esto implica disparidades en los niveles de calidad, a veces con experiencias que permanecen heterogéneas o irregulares, a pesar de que sean el objeto de una atención particular por parte de las autoridades civiles zapatistas que han puesto la educación en el corazón de los proyectos de autonomía política en los cuales “[...] el pueblo manda y el gobierno obedece”, según la fórmula consagrada.

Con el nombramiento del educador de manera interna por medio de asambleas, cargos y rendición sistemática de cuentas, los sujetos involucrados se apropian la escuela mostrando qué formas alternativas de gestión comunal permiten la emergencia de prácticas de alfabetización que son propicias para la enseñanza de conocimientos ligados a los contextos socioculturales. Los saberes escolares que valorizan las familias son entendibles en la expresión de la demanda indígena de hacer de la escuela un espacio privilegiado de la producción y circulación de saberes de los pueblos originarios y la reproducción del imaginario social y político, en particular las memorias colectivas y las identidades culturales. Así la otra escuela en construcción plantea la cuestión del aprendizaje situado y colaborativo en términos de conocimientos y valores que participan en la descolonización de la sociedad, partiendo de la puesta en práctica pedagógica de compromisos éticos ${ }^{6}$. 
La Educación Zapatista como Base de la Autonomía en el Sureste Mexicano

En varias de las propuestas educativas, como en el Municipio autónomo Ricardo Flores Magón, el aprendizaje situado se entrecruza en talleres cooperativos en cuatro áreas de conocimiento integradas: Vida y medioambiente, Historias, Lenguas y Matemáticas. Por ejemplo, en cuanto a la demanda Tierra, los promotores preparan actividades pedagógicas relacionadas con el tema agrario y el maíz. Para la materia de ciencias naturales se formulan preguntas generadoras sobre la protección y utilización de los recursos ambientales. Para las materias de historia y ciencias sociales, se estudian los movimientos de lucha por la tierra en Chiapas y en México, así como en el mundo cuando por ejemplo se aborda el movimiento Sem Terra y la lucha mapuche. En la enseñanza de la geometría, se miden parcelas y cosechas. Como ejercicios de español se pueden redactar poemas sobre la naturaleza y cartas virtuales de denuncia por amenazas de despojo.

La autonomía educativa obliga a innovar, a buscar modos de organización y de aprendizaje nuevos y además parece indisolublemente ligada a la transformación de las relaciones de poder en otros sectores de la vida social. Sin embargo, en términos sociológicos, se pueden vislumbrar las demandas y experiencias alternativas del movimiento indígena como una señal más del proceso de reafirmación identitaria que sostiene desde hace pocas décadas, pero que se manifiesta con mucha claridad en los Municipios autónomos en México (Baronnet, 2011, p. 138). Para comprender desde el campo educativo los cambios en la cultura política y la identidad étnica es preciso analizar la producción de las identidades, historizando por un lado las formas en que los nombres atribuidos han construido identidades y reproducido las asimetrías de poder, y constatando por otro lado que las identidades son inestables y que nunca son efecto inequívoco del proceso de enunciación hegemónica (Corona, 2009). La construcción de un sistema de educación autónomo no está exento de las lógicas de poder institucional que se disputan la legitimidad de aparecer como una propuesta alternativa de raíz comunitaria, que recupera la historia de los sujetos de los pueblos; esto es, el quehacer cotidiano donde se forjan las identidades colectivas vistas como "[...] procesos no necesariamente apreciados desde una óptica muy exterior” (Stahler-Sholk, 2013).

De alguna manera, la autonomía educativa garantiza pero no vuelve hegemónica la enseñanza de conocimientos culturalmente diferenciados en más de quinientas escuelas que cuentan entre uno y una decena de promotores educativos en servicio y en formación en cada municipio. En vez de focalizar la enseñanza en la esencia folklorizante de la etnicidad, las autonomías indígenas se inclinan a favorecer un modo original de articular conocimientos sociales diferenciados desde el punto de vista cultural. Los valores y las demandas sociales de la organización zapatista son los elementos políticos que articulan la organización de los contenidos escolares abordados por los promotores, por

718 Educação \& Realidade, Porto Alegre, v. 40, n. 3, p. 705-723, jul./sept. 2015. 
ejemplo a partir de proyectos pedagógicos basados en la cuestión de la tierra, de los derechos y las libertades.

Así, la interculturalidad crítica en la educación responde a una lógica de negociación interna permanente y en tensión entre lo culturalmente endógeno y lo exógeno; siendo elegidos, autorizados y controlados los actores externos que intervienen indirectamente en el proceso de selección y formación de los contenidos. Al apropiarse del control de sus escuelas, las asambleas de las comunidades y los municipios zapatistas están redefiniendo las prioridades, las necesidades y los criterios de la calidad y pertinencia que exigen del sistema alternativo autogestivo desde hace cerca de dos décadas en la Selva Lacandona, los Altos y el Norte de Chiapas. Como partícipes de las pedagogías de la liberación india en construcción, los campesinos implicados en procesos de resistencia política contribuyen a afianzar y reafirmar las conciencias subjetivas de pertenecer a un grupo socioétnico y político determinado. Sin embargo, más que un reto utópico, el sentido emancipador que otorgan las familias zapatistas a su proyecto político de transformación social y educativa parece inscribirse en una lógica de redefinición permanente de lo que se espera de la escuela comunitaria; lo que contribuye al final a reafirmar rasgos identitarios de los grupos considerados por medio de ella (Baronnet, 2013; Gómez Lara, 2011; Núñez, 2011). En algunas comunidades campesinas del Sur de México, como en Oaxaca y Chiapas, están surgiendo condiciones que permiten una integración selectiva de elementos culturales y lingüísticos heredados, junto con la apropiación de otras formas de conocimiento de orígenes externos pero que son vitales en la localidad para la supervivencia (Rockwell, 2011, p. 99).

Asimismo, la educación en los Municipios autónomos es ante todo praxis en movimiento, no solo desde la interpretación intersubjetiva sino transformando la realidad social. El mero conocimiento como abstracción pura, sin sentido práctico, no tiene mucha relevancia aparente en las maneras de ser, actuar y pensar el mundo. Partiendo del estudio de las demandas políticas del movimiento, se aprende y construye para sobrevivir, luchar y resistir las políticas de despojo en un contexto de guerra y de recursos materiales limitados.

\begin{abstract}
Nosotros no tenemos nada y por eso estamos luchando y tenemos 13 demandas, nosotros queremos nacer la educación de cada demanda porque como indígenas queremos una vida mejor y si el mal gobierno no cumple, si no lo hace, pues lo hacemos nosotros porque tenemos el derecho y porque ya estamos en tiempo de hacerlo y así lo vamos a hacer con todos los trabajos (Municipio Autónomo en Rebeldía Ricardo Flores Magón, 2001).
\end{abstract}

Desde una epistemología del sur y la óptica decolonial (Santos, 2010; Walsh, 2009), se requiere observar y analizar las realidades culturales con base en la práctica de los actores sociales que no se pueden idealizar ni esencializar, en la medida en que reconozcamos que son 
La Educación Zapatista como Base de la Autonomía en el Sureste Mexicano

los propios sujetos los que nos obligan a mirar críticamente y reaccionar contra las instituciones y las estructuras de dominación que han impuesto silencio e inmovilización. Así, se plantea no sólo la necesidad de "[...] imaginar soluciones realmente novedosas - basadas en prácticas y modos 'otros' de educar, gobernar, saber, hacer, ser y vivir - sino también asegurar que estas imaginaciones se concreten" (Walsh, 2009, p. 212). En el proceso de construcción de una democracia intercultural y de refundación del Estado, Boaventura de Sousa Santos (2010, p. 108109) identifica que una dificultad para el debate civilizatorio del cual parte la epistemología del sur radica en que presupone una educación pública (ciudadana y comunitaria) adecuada para la creación de un nuevo sentido común intercultural, lo que implica otras mentalidades y subjetividades.

\section{Conclusión}

En una sociedad democrática que lucha contra las discriminaciones en su seno, la educación intercultural se vuelve factible y viable si su organización administrativa y pedagógica deja de depender, por una parte, de la tutela de instituciones públicas en las cuales no participan de manera directa los representantes legítimos de los pueblos originarios, y por otra parte, y de la acción y el interés de profesionistas de la enseñanza que no siempre comparten las condiciones socioculturales y los proyectos etnopolíticos de las comunidades donde son docentes. Asimismo, la participación activa de los jóvenes y adultos en el marco de una democracia comunitaria se erige en una condición necesaria para que de su intervención emerjan proyectos autonómicos de naturaleza emancipadora y descolonizante.

A veinte años del levantamiento armado, la educación zapatista representa una de las bases de la autonomía en el Sureste mexicano en la medida en que los pueblos mayas zapatistas desempeñan prácticas que desafían a la política educativa del Estado, al participar mediante cargos y asambleas en la construcción de la escuela, la selección y la manutención de educadores comunitarios y la formación de los mismos. Los cambios en la organización comunitaria de la educación tienen como consecuencia prácticas pedagógicas críticas y descolonizantes en torno a los contenidos escolares relacionados con el contexto sociopolítico y cultural. Si bien las demandas zapatistas se orientan a resignificar y apropiarse la escuela como espacio de afianzamiento de las identidades políticas y socioculturales, al mismo tiempo los procesos de construcción educativa están basados en los recursos simbólicos y las identidades que dan sentido al imaginario colectivo y a las acciones sociales.

No sin dificultades, la autonomía política educativa implica que la definición del quehacer educativo dignifica en la praxis las especificidades identitarias de las comunidades indígenas. Con formas organizativas y recursos propios, los contenidos escolares son propuestos 
y discutidos libremente por las familias, autoridades y educadores comunitarios. Lejos de ser sistemas educativos homogéneos y homogenizantes, comparten principios éticos y democráticos al implementar políticas propias de educación donde se ve reflejada la construcción cotidiana de las identidades. Así, los jóvenes indígenas zapatistas que nacieron y crecieron después de 1994 representan ahora los actores clave de los procesos de transformación social que caracterizan a la vida cotidiana de las comunidades autónomas. Según el proyecto escrito del Municipio Autónomo en Rebeldía Ricardo Flores Magón (2001), el fin y principio de toda educación que se considere verdadera desde la concepción zapatista se refiere a que "un día los niños y las niñas van a tener cargo en su comunidad o en el municipio y así pueden resolver el problema y cumplir con las demandas que deben cumplir como autoridad de su pueblo porque ellos deben mandar obedeciendo".

Recibido en 20 de marzo 2014 Aprobado en 11 de agosto 2014

\section{Notas}

1 Este artículo proviene de un trabajo de investigación participativa realizado en Chiapas, México, entre 2004 y 2007 en el marco de una tesis doctoral en Sociología realizada en El Colegio de México y la Universidad de París Sorbona Nueva (2009), así como de reflexiones posteriores cuyos principales resultados han sido publicados en los textos del autor citados en la bibliografía (Baronnet, 2011 ; 2012; 2013).

2 Esta etapa significó la ruptura hasta ahora de toda forma de diálogo entre las partes en conflicto, y la puesta en práctica unilateral por parte de los Municipios autónomos de los derechos a la autodeterminación a nivel político-organizativo, articulando el campo de la educación con los demás ámbitos de la política autónoma del buen vivir (lekil kulejal en tzeltal).

3 El proceso de construcción autonómica en condiciones de conflicto en el estado fronterizo de Chiapas está inspirando en su conjunto a otros sectores de los movimientos indígenas de México al declarar algunas zonas bajo su influencia como municipios autónomos en estados de la República como Michoacán, Oaxaca, Puebla y Guerrero.

4 Según Freire, pertenecer a un grupo cuyos miembros se concientizan unos a otros a través de su trabajo cotidiano significa que ellos se muestren capaces de develar colectivamente y mediante el diálogo la razón de ser de las cosas, como el porqué de la explotación. Sin embargo, "este descubrimiento debe ir acompañado de una acción transformadora, de una organización política que posibilite dicha acción, o sea una acción en contra de la explotación" (Escobar, 1985, p. 154).

5 Este proceso descolonizante de enseñanza-aprendizaje es visto como un proceso liberalizador, emancipatorio y generador de ideas como el surgimiento de "otra escuelita" que muestra y demuestra las maneras de ser y hacer de los zapatistas a la que convocó el EZLN el 15 de febrero de 2013 a través del Subcomandante Insurgente Moisés. 
La Educación Zapatista como Base de la Autonomía en el Sureste Mexicano

6 Los siete principios rectores del buen gobierno en distintos niveles consisten en obedecer y no mandar, representar y no suplantar, construir y no destruir, unir y no dividir, servir y no servirse, bajar y no subiry proponer y no imponer.

\section{Referencias}

BARONNET, Bruno. L’Expérience d'Éducation Zapatiste au Chiapas: entre pratiques politiques et imaginaires autochtones à l'école. Cahiers de la Recherche sur l'Éducation et les Savoirs, Paris, ARES, n. 12, p. 133-152, abr. 2013.

BARONNET, Bruno. La Autonomía Zapatista en su Lucha por Otra Educación: un reto a la política educativa indígena en México. In: CAMACHO, Dolores; LOMELÍ, Arturo; LÓPEZ, Artemisa (Coord.). El Campo Mexicano sin Fronteras: alternativas y respuestas compartidas. Tomo 4, Pueblos indios, autonomía y organizaciones sociales. México, UNAM/AMER, 2012. P. 33-55.

BARONNET, Bruno. Autonomía Educativa Zapatista: hacia una pedagogía de la liberación india en Chiapas. Em Aberto, Brasília, v. 24, n. 85, p. 127-144, abr. 2011. BOURDIEU, Pierre. Sociología y Cultura. México: Grijalbo/Conaculta, 1990.

BOURDIEU, Pierre. Systèmes d'Enseignement et Systèmes de Pensée. Revue Internationale des Sciences Sociales, Paris, v. 19, n. 3, p. 367-388, 1967.

CORONA BERKIN, Sarah. Dos Fuentes de la Etnicidad Indígena: las políticas públicas y los procesos de emancipación. In: MEDINA, Patricia (Coord.). Epistemologías de la Diferencia: debates contemporáneos sobre la identidad de las prácticas educativas. México: Universidad Pedagógica Nacional/CONACYT/ Plaza y Valdés editores, 2009. P. 49-58.

DIETZ, Gunther; MATEOS, Laura. Interculturalidad y Educación Intercultural en México: un análisis de los discursos nacionales e internacionales en su impacto en los modelos educativos mexicanos. México: SEP-CGEIB, 2011.

ESCOBAR, Miguel. Paulo Freire y la Educación Libertadora. México: SEP, 1985.

ESCUELITA ZAPATISTA. Gobierno autónomo II. Cuaderno de texto de primer grado del curso de “La libertado según 1@s zapatistas”. Chiapas, agosto de 2013.

FREIRE, Paulo. Un diálogo con Paulo Freire sobre educación indígena. In: AMÓDIO, Emanuele (Comp.). Educación, Escuelas y Culturas Indígenas de América Latina. Quito: Abya-Yala, 1986. P. 115-151.

GÓMEZ LARA, Horacio. Indígenas, Mexicanos y Rebeldes: procesos educativos y resignificación de identidades en Los Altos de Chiapas. México: Juan Pablos/ UNICACH, 2011.

HENAFF, Nolwen; LANGE, Marie-France. Inégalités Scolaires au Sud: transformation et reproduction. Autrepart, Paris, IRD/Presses de Sciences Po, n. 59, p. 3-18, 2011.

JUNTA DE BUEN GOBIERNO DE OVENTIK. La JBG de Oventik informa sobre la situación de las bases de apoyo desplazados y denuncia la represión del mal gobierno. Enlace Zapatista, Chiapas, 13 de octubre de 2010.

MUNICIPIO AUTÓNOMO EN REBELDÍA RICARDO FLORES MAGÓN. La Educación Verdadera. La Culebra, mimeo, 2001.

NOLASCO ARMAS, Margarita. La Condición Indígena en el siglo XXI. Del indio "indito" a los indígenas mexicanos. In: GUTIÉRREZ, Javier; CUADRIELLO, Hadlyyn (Coord.). Los Pueblos Indígenas de Chiapas. México: INAH/ENAH, 2009. P. 13-48. 
NUÑEZ, Kathia. De la casa a la escuela zapatista. Prácticas de aprendizaje en la región ch'ol. In: BARONNET, Bruno; MORA, Mariana; STAHLER-SHOLK, Richard (Coord.). Luchas "muy otras”. Zapatismo y autonomía en las comunidades indígenas de Chiapas. México: UAM-Xochimilco/CIESAS/UNACH, 2011. P. 267-294.

ROCKWELL, Elsie. Repensando el trabajo educativo y cultural en tiempos de guerra. In: MEYER, Lois; MALDONADO, Benjamín (Ed.). Comunalidad, Educación y Resistencia Indígena en la Era Global. Oaxaca: CSEIIO, 2011. P. 87-101.

SANTOS, Boaventura de Sousa. Refundación del Estado en América Latina: perspectivas desde una epistemología del Sur. Lima: Instituto Internacional de Derecho y Sociedad, Programa Democracia y Transformación Global, 2010.

STAHLER-SHOLK, Richard. Ser el Cambio que uno Quiere Ver: identidad colectiva y prácticas de autonomía en las comunidades zapatistas de Chiapas. In: INTERNATIONAL CONGRESS, LATIN AMERICAN STUDIES ASSOCIATION (LASA), 31, mayo 2013, Washington D.C. Washington D.C., mayo 2013.

STAVENHAGEN, Rodolfo. La Política Indigenista del Estado Mexicano y los Pueblos Indígenas en el Siglo XX. In: BARONNET, Bruno; TAPIA, Medardo (Coord.). Educación e Interculturalidad: política y políticas. Cuernavaca: CRIM-UNAM, 2013. P. 23-48.

WALSH, Catherine. Interculturalidad, Estado, Sociedad: luchas (de)coloniales de nuestra época. Quito: Universidad Andina Simón Bolívar, Ediciones Abya-Yala, 2009.

ZIBECHI, Raúl. Territorios en Resistencia: cartografía política de las periferias urbanas latinoamericanas. Buenos Aires: Lavaca Editora, 2008.

Bruno Baronnet es profesor e investigador en Antropología y Estudios Interculturales en el Instituto de Investigaciones en Educación de la Universidad Veracruzana, en Xalapa, México. Sus trabajos actuales versan sobre la formación de profesores bilingües y las estrategias de distintos actores de los pueblos originarios en torno a las políticas y las prácticas de educación intercultural en América Latina.

E-mail: bruno.baronnet@gmail.com 